\title{
GUILLEM DE MEDIONA A LA BATALLA DE PORTOPÍ
}

\author{
Martí de Riquer
}

Una de les escenes més belles i impressionants del murals del segle XIII del palau Aguilar del carrer de Montcada de Barcelona, avui al Museu d'Art de Catalunya, és aquella que presenta Guillem de Montcada, vescomte de Bearn, lluitant a cavall a la batalla de Portopí (12 de setembre del 1229), la primera acció militar de la conquesta de Mallorca!.

Es tracta, com és sabut, de Guillem II, el qual l'any 1223 heretà el vescomtat de Bearn, incorporat a la línia del seu llinatge des que, el 1170, el seu avi Guillem I de Montcada s'havia casat amb Maria, vescomtessa de Bearn. Des del punt de vista heràldic, els Montcada vescomtes de Bearn autoritzaven llurs documents amb segells on figuraven les vaques bearneses i només sis besants de les armes de Montcada, mentre que els seus parents, els Montcada de la línia dels grans senescals, seguien usant únicament l'escut amb vuit besants, forma plena en oposició a la reducció que constitueix la diferència o brisura que caracteritza el blasó d'aquells².

1 Veg. J. Ainaud De LaSARTE, Pintures del segle XIII al carrer de Montcada de Barcelona, pp. 20-22, discurs de recepció a la Reial Acadèmia de Bones Lletres de Barcelona, 1969.

2 Veg. M. DE RIQUer, Heràldica catalana des de l'any 1150 al 1550, I, Barcelona 1983, pp. 170-173. 
Els dos Montcada que moriren a la serra de Portopí el 1229 pertanyien cadascum a una d'aquestes línies del llinatge. Era l'un Ramon de Montcada el Jove, germà menor de Guillem Ramon V senescal de Catalunya i que es casà amb Constança d'Aragó, filla bastarda del rei Pere el Catòlic. Hom pot donar com a segur que l'estendard de gules amb vuit besants d'or que apareix al seguici de cavallers dels murals del saló del Tinell de Barcelona és el de Ramon de Montcada el Jove, per tal com la seva línia no reduìa el nombre de peces.

A la susdita escena del mural del palau Aguilar, el cavaller que hi és més destacat du emblemes heràldics a l'escut que abraça, a la cervellera, a la gropera i la testera del cavall, i així mateix al penó que va pintat darrere seu, armes que porten de gules sis besants d'or amb un cap, o xef, d'argent amb dues vaques de gules ${ }^{3}$. Això identifica aquest cavaller amb Guillem II de Montcada, vescomte de Bearn, mort gloriosament en aquella acció de Portopí, com també el seu oncle Ramon el Jove, el qui portava les armes plenes de Montcada: de gules vuit besants d'or.

Tot això és sabut i admès. Ara bé, al mural del palau Aguilar, l'escena que estudiem presenta dos cavallers lluitant contra els sarraïns completament sols i separats de la host cristiana: i així, molt junt darrere Guillem de Montcada i combatent al seu costat, apareix un altre cavaller, també muntat i brandint una llança, i tan unit a ell per l'artista que el penó de Montcada s'alça darrera seu com si aquest cavaller pertangués a la mainada del vescomte. Aquest cavaller que, malgrat la seva col·locació secundària, és l'únic company d'armes de Guillem de Montcada, deixa veure la seva heràldica personal a l'escut que abraça, a la cervellera i a la gropera del cavall, blasó que podem definir així: de gules amb un cap, o xef, amb faixes undees d'argent $\mathrm{i}$ d'atzur.

Un escut faixé, o faixat, de sis o vuit peces undees d'argent i d'atzur és vell i il-lustre en heràldica catalana, car constitueix les armes dels varvassors de Mediona ${ }^{4}$. Això identifica el llinatge del ca-

3 Veg. la il-lustració en color a RIQUER, Heràldica catalana II, p. 465, làmina 124.

${ }^{4}$ Cf. RiQuer, Heràldica catalana I, p. 137, núm. 73. 
valler pintat al mural; però potser indica que aquest no era el titular de la varvessoria o que pertanyia a una línia que brisava o es diferenciava respecte de les armes plenes del llinatge, posant-les al cap o xef. I hem de rebutjar qualsevol error heràldic en un mural sempre tan rigorós en la reproducció d'emblemes personals.

L'escena del mural del palau Aguilar correspon exactament a un episodi de la batalla de Portopí que narra Desclot:

E quant los sarraÿns ho viuren, foren-ne molt irats, e partirense de lur host bé xII mflia e montaren-se'n ves lo pug hon En Guilem de Moncada era. E quant En Guilem de Moncada los viu venir, dix a ssos cavalés: - Barons - dix él-, anats-los ferir, e yo romandré assí ab sol I cavaler; que si el puyg podem retenir, la batayla avem guaanyada.- Ab tant los cavalers puyiren ves los sarrayns e anaren ferir en éls, sí que-ls vaỹren e passaren d'oltra; mas tant era gran la pressa dels sarraỹns, que no pogren tornar e-l puyg a-N Guillem de Moncada. E els sarraȳns montaren e.l puyg, e En Guilem de Moncada, qui-ls viu venir, volc-lur escapar, per ço cor no era mas ab I cavaler, mas no poc devalar ab lo caval, que la montanya era molt rosta e arrocada. E tornà atràs e volc pendre altra carrera, mas los sarrayns lo sobtaren tan fort de totes parts, que no-s poc deffendre, e pres I colp en la cama, que-I peu li caech en terra: e puys auceïren-li son caval, e caech de tot en terra e aquí morí. E el cavaler qui ab él era, mentre que els seraÿns se conbatien ab En Guilem de Moncada, deffensà-se al mils que poc; e puys, quant viu que son senyor fo mort, escapà als sarayns, e malament nafrat e.1 cap e en la cara, e tornà-sse'n ves los crestians'.

Zurita, que segueix ací la narració de Desclot, aventura qui fou el cavaller que lluità al costat de Guillem de Montcada fins que aquest mori:

Escribe que entonces hasta doce mil moros de caballo y de pie los siguieron por el recuesto arriba y comenzaron a pelear firmemente y los nuestros los desbarataron. Pero que era tanta la multitud de los moros que no pudieron tornar a cobrar el cerro a donde había quedado el vizconde solo con un caballero; y queriendo pasar

5 Edició de M. Coll i Alentorn, B. Desclot, Crònica II, Barcelona 1949, pp. 104-105, col. «Els Nostres Clàssics». 
por ellos la cuesta abajo, no pudo por ser muy enhiesta; y retirándose el vizconde atrás para tomar otra vereda, fue cercado de los moros y le hirieron en la pierna de tal golpe que le cortaron el pie. Entoces le mataron el caballo y cayó a tierra y fue allí muerto; y el caballero que estaba con él - que Aclot no nombra, debe ser el que en la historia del rey don Jaime se llama Guillén de Medionamientras pelearon se defendió lo mejor que pudo; $y$ viendo que su señor era muerto, se escapó huyendo6.

Zurita intuí qui era el cavaller del qual Desclot calla el nom perquè deduí aquest d'un passatge del Libre dels feyts on es parla de Guillem de Mediona, que tenia fama d'ésser el cavaller que millor junyia de tot Catalunya, segons l'alt testimoni del rei Jaume. Escriu aquest, narrant la batalla de Portopí i poc abans de la mort de Guillem de Montcada:

E encontram En G. de Mediona, que deyen que en tota Cathalunya nuyl hom no junyia mils que él, e era bon cavaller; e exia's de la batallya, e exia'l sanch per lo labi dessús de la boca. E dixemli: - En G. de Mediona, con exits de la batayla? - E dix él: - Car só ferit-. E cuydam nós que fos ferit de colp mortal que tingués pel cors. E dixem: - E de què sots ferit?-, - D'una pedra que $\mathrm{m}$ 'an dat sus en la boca só ferit-. - E sofrits! - dixem nós; e prenguem-lo per las regnas, e dixem-li: - Tornats a la batayla, que bon cavaller per aytal colp con aquel enfelonir se'n deu, que no deu exir de batayla -. E a cap d'una peça que nós lo gardam, no-1 vim?

Que existia íntima relació entre Guillem de Montcada, vescomte de Bearn, i Guillem de Mediona ho demostra un document signat a Salou el primer de setembre del 1229, o sia, quan l'estol de Jaume I estava a punt de salpar vers Mallorca, en el qual el vescomte subscriu com a testimoni de l'escriptura de la concessió del castell de Castellet feta per Jaume I a Saurina de Castellet, muller de Guillem de Mediona ${ }^{8}$. No sembla, car no ho diuen ni el Libre dels feyts ni

6 J. ZurrtA, Anales de la Corona de Aragón I, lib. III, cap. IV, edició d'A. Canellas, Zaragoza 1976, pp. 443-444.

7 Libre dels feyts, $\$$ 64, edició Jaume I, Crònica II, Barcelona 1927, pp. 40 42, «Col-lecció Popular Barcino».

8 J. MiRET Y SANS, *La casa de Montcada en el vizcondado de Bearn*, Boletín de la Real Academia de Buenas Letras de Barcelona I, 1901-1902, p. 288. 
la Cronica de Desclot, que Guillem de Mediona morís a la campanya de Mallorca, i potser cal identificar-lo amb un Guillem de Mediona que figura en un document de l'any $1231^{\circ}$, encara que la reiteració del mateix nom de fonts al llinatge no permeti de donar-ho per segur.

Crec, doncs, que el meravellós document gràfic que és el mural del palau d'Aguilar corrobora la conjectura de Zurita, el qual veié en Guillem de Mediona l'únic cavaller que combaté al costat de Guillem de Montcada a la batalla de Portopí pocs moments abans de la mort del vescomte. I encara que, mort aquest, tornés al gros de la host catalana greument ferit al cap i a la cara, com recull Desclot, el cert és que el rei Jaume sabia «que deyen que en tota Cathalunya nuyl hom no junyia mils que él, e era bon cavaller». L'artista del nostre mural l'ha pintat atacant un enemic molt poderós, donant-li la cara amb uns ulls molt oberts i amenaçant-lo amb la llança.

9 Veg. la nota de F. Soldevila al $\$ 64$ del Libre dels feyts en Les quatre grans cròniques, Barcelona 1971, p. 230, «Biblioteca Perenne». 